\title{
Enhancement of flavor aversion conditioning in weanling but not adult rats by prior conditioning to an odor
}

\author{
PHILIPP J. KRAEMER, ELIZABETH GORDON KRAEMER, DREW E. SMOLLER, \\ and NORMAN E. SPEAR \\ State University of New York at Binghamton, Binghamton, New York
}

\begin{abstract}
In four experiments, we tested the effect of signaled and unsignaled preexposure to the US on conditioning of a taste aversion to saccharin, which was induced by pairing the saccharin (CS) with lithium chloride (US). Rats of two ages were tested, weanlings 21 days old at the time of conditioning and adults 60-80 days old at the time of conditioning. The procedures generally were designed to minimize the deleterious effects of US preexposure on conditioning in adults. In Experiment 1, preexposure to a US signaled by a novel odor (banana) facilitated conditioning in the weanlings but not in the adults. In Experiments $2 \mathrm{~A}$ and $2 \mathrm{~B}$, these results were completely replicated. Only the weanlings were tested in the final experiment, in which it was determined that saccharin-LiCl conditioning was again facilitated by a prior pairing of the banana odor and $\mathrm{LiCl}$, but only if the $\mathrm{LiCl}$ doses $(.15 \mathrm{M}$ or $.30 \mathrm{M})$ were the same for the signaled US preexposure and for the taste-aversion conditioning itself. In all of these experiments, a conditioned aversion to saccharin paired with $\mathrm{LiCl}$ was enhanced by prior pairing of an unrelated odor with $\mathrm{LiCl}$, in the weanlings but not the adults. These results agree with others in suggesting that during the first three postnatal weeks rats may have a special disposition for cross-modal transfer.
\end{abstract}

One of the well-established phenomena of Pavlovian conditioning is the unconditioned stimulus (US)preexposure effect. Numerous studies have shown that prior experience with a US attenuates subsequent conditioned responding to the conditioned stimulus (CS) (e.g., Randich \& LoLordo, 1979). One version of this phenomenon is the so-called drug-preexposure effect, found with conditioned taste aversions. In this instance, weaker taste aversions are found in animals that have had prior experience with a drug than are found in drug-naive animals (Bravemen, 1975; Cannon, Berman, Baker, \& Atkinson, 1975; Cappell \& LeBlanc, 1975; Elkins, 1974; Mikulka, Leard, \& Klein, 1977; Riley, Jacobs, \& LoLordo, 1976). To date, however, all the published studies have employed adult rats, and whether a similar effect is to be found in immature rats remains an empirical question of potential significance.

There now exists clear evidence that immature rats can acquire strong conditioned taste aversions (Gemberling \& Domjan, 1982; Gemberling, Domjan, \& Amsel, 1980; Hoffmann, Molina, Kucharski, \& Spear, 1987). In addition, taste-aversion phenomena found in adults have also been found in younger rats, although there are some im-

The present research was supported by grants from the National Institute of Mental Health (I ROI MH35219 to Norman E. Spear and I RO3 MH42992 to Philipp J. Kraemer). The authors would like to thank Norman G. Richter for his technical assistance and Teri Tanenhaus for preparation of the manuscript. Address correspondence to Norman E. Spear, Center for Developmental Psychobiology, Department of Psychology, SUNY Binghamton, Binghamton, NY 13901. portant age-related differences in the nature of these phenomena (see Kraemer, Hoffmann, \& Spear, 1988). The initial purpose of this study was to examine possible drug-preexposure effects in immature rats, and to assess potential ontogenetic differences in such effects. Any age-related difference in the effects of drug preexposure could have important theoretical implications for our understanding of the ontogeny of learning and memory.

\section{EXPERIMENT 1}

Experiment 1 was designed to answer three primary questions. First, we compared adults and weanlings with respect to the effects of drug $(\mathrm{LiCl})$ preexposure on conditioning of a saccharin aversion that was induced by pairing saccharin with the drug. Second, we tested two different drug intensities at both ages. Research on adults has shown that higher drug intensities increase the magnitude of both the attenuation effect of drug preexposure and the absolute level of aversion strength in nonpreexposed animals (Cannon et al., 1975). In this experiment, we varied the drug intensity by employing two concentrations of $\mathrm{LiCl}$. Separate preexposed groups at each age received either $.15 \mathrm{M}$ or $.3 \mathrm{M} \mathrm{LiCl}$ injections prior to a conditioning episode, in which saccharin was paired with $\mathrm{LiCl}$ of the same concentration as was used during preexposure.

The final question concerned possible age-related differences in the effects of signaled and unsignaled drug preexposure. Evidence from adults has indicated that signaled preexposure either produces less of an attenuation effect 
than unsignaled preexposure (Cannon et al., 1975) or has no attenuating effect at all (Mikulka et al., 1977). In Experiment 1 , signaled preexposure consisted of a paired presentation of an explicit odor cue with injection of $\mathrm{LiCl}$ the day before conditioning, and unsignaled preexposure involved presentation of the drug alone.

It was in transfer from the odor- $\mathrm{LiCl}$ episode to the conditioned gustatory aversion that there was reason to expect an age-related difference. A variety of experiments summarized by Spear \& Molina (1987) and Spear, Kraemer, Molina, and Smoller (1988) indicate that infants may be more likely than adults to transfer conditioning in one sensory modality to conditioning in another modality. On this basis, we expected that weanlings in Experiment 1 might show enhanced gustatory (saccharin) conditioning when the saccharin- $\mathrm{LiCl}$ pairing was preceded by an odor-LiCl pairing. The literature indicated that adults would be unlikely to show such an effect with the present procedures. There is no precedent for determining whether ontogenetic differences might be observed in the effects of prior unsignaled $\mathrm{LiCl}$ on saccharin- $\mathrm{LiCl}$ conditioning.

\section{Method}

Subjects. The subjects were 60 adult and 120 weanling (derived from 15 litters) Sprague-Dawley rats, born and reared in the colony at SUNY-Binghamton. The adults were weaned on Postnatal Day 21 , the normal time of weaning for rats in our colony, and they were individually housed in standard hanging metal cages. All the adults were placed on a 23.5 -h water deprivation schedule 7 days prior to the beginning of the experiment. The weanlings were weaned and deprived of water on Postnatal Day 19. They were group-housed in plastic maternity cages throughout the course of the experiment. Both the weanlings and the adults were housed in the same climate-controlled vivarium, which was maintained on a 16:8-h light:dark cycle. All testing occurred during the light phase of the cycle.

Apparatus. Three different test rooms were used for each of the three preexposure conditions, and a fourth room was used for conditioning and testing. The rooms, all similar in appearance, contained individual metal hanging cages. The weanlings were administered liquids in 10-ml graduated drinking tubes, and the adults received liquids in 100-ml graduated tubes. During administration of the liquid, the tubes were attached to the front of each test cage. All the liquids were dispensed at room temperature. The taste CS was a $.15 \%$ saccharin solution. Drug injections consisted of either $.15 \mathrm{M}$ or $.3 \mathrm{M} \mathrm{LiCl}$, administered intraperitoneally at a $1 \%$ bodyweight-dose level.

Procedure. Two drinking adaptation sessions on consecutive days were given in the conditioning-test room. The first session occurred on Postnatal Day 20 for the weanlings, and for animals of both ages, each session involved $30 \mathrm{~min}$ of exposure to tap water. Drug preexposure occurred $5 \mathrm{~h}$ after the second adaptation session. The groups given signaled preexposure were placed in individual cages for $.5 \mathrm{~h}$ in the presence of the odor cue. The odor consisted of $2 \mathrm{cc}$ of banana extract (Virginia Dare Co.) placed on paper below each cage. After $.5 \mathrm{~h}$ exposure to the odor, these animals received their drug injection, and they were then immediately returned to the preexposure cage, where they remained for an additional $2 \mathrm{~h}$. The animals given unsignaled preexposure were treated similarly, except that no odors were explicitly provided during the preexposure interval. The nonpreexposed animals were placed in individual cages for the same duration as the animals in the preexposure groups, but they received no drug injections at this time. Each preexposure condition (signaled, unsignaled, and none) was conducted in a separate experimental room.

Conditioning occurred the day after the preexposure session. Each subject was placed in a test cage with a bottle containing saccharin attached to the front. Following $.5 \mathrm{~h}$ of exposure to saccharin, each subject received an IP injection of the appropriate $\mathrm{LiCl}$ concentration and was then returned to the home cage. Testing took place $24 \mathrm{~h}$ after conditioning, and involved $.5 \mathrm{~h}$ of simultaneous access to two bottles, one containing saccharin and the other tap water. The left/right placement of the two bottles was randomly varied across subjects. Liquid consumption during conditioning and testing was recorded to the nearest $.1 \mathrm{ml}$ for the weanlings and to the nearest $1 \mathrm{ml}$ for the adults. All statistical analyses incorporated an alpha level of .05

\section{Results and Discussion}

The consumption during conditioning did not differ significantly among the weanlings, but it did among the adults. The adults conditioned with $.3 \mathrm{M} \mathrm{LiCl}(M=22.3)$ consumed significantly more than the adults conditioned with $.15 \mathrm{M} \mathrm{LiCl}(M=18.5)$. Although there were no significant differences among the adults as a function of preexposure experience, and the preexposure experience $x$ drug intensity interaction was not significant, there was a tendency for the signaled and unsignaled preexposed groups given $.15 \mathrm{M} \mathrm{LiCl}$ to consume less than the similarly treated groups given $.3 \mathrm{M} \mathrm{LiCl}$. This tendency may have contributed to the overall increased consumption for the adults given $.3 \mathrm{M} \mathrm{LiCl}$. Other than the hypertonicity of the $.3 \mathrm{M} \mathrm{LiCl}$ and the possible influence of this factor, we can offer no obvious explanation for these differences.

A preference score was calculated for each animal's test consumption, according to the following formula: (amount saccharin/total fluid consumed) $\times 100$. The mean saccharin preferences for the weanlings and the adults in the three preexposure conditions, collapsed over drug intensity, are presented in Figure 1. Separate analyses of variance were performed on the data from the weanlings and the adults. The two factors in these analyses were preexposure experience (odor- $\mathrm{LiCl}, \mathrm{LiCl}$ alone, and none) and drug intensity $(.15 \mathrm{M}$ and $.3 \mathrm{M} \mathrm{LiCl})$. The analysis for the adult preferences indicated no significant main effects of either preexposure experience or drug intensity, and the interaction between these factors was also not significant. Thus, neither drug preexposure nor drug intensity affected saccharin preferences in adults.

As can be seen in Figure 1, differences in saccharin preferences did appear among the weanlings. Significant main effects were obtained for both preexposure experience $[F(2,114)=3.4]$ and drug intensity $[F(1,114)$ $=24.7]$, but the preexposure $\times$ drug intensity interaction was not significant. Individual group comparisons revealed that the weanlings conditioned with $.3 \mathrm{M} \mathrm{LiCl}$ $(M=9.0)$ expressed significantly stronger aversions (lower saccharin preferences) than did the weanlings conditioned with $.15 \mathrm{M} \mathrm{LiCl}(M=28.1)$. As is seen in Figure 1, the weanlings preexposed to odor- $\mathrm{LiCl}$ ex- 


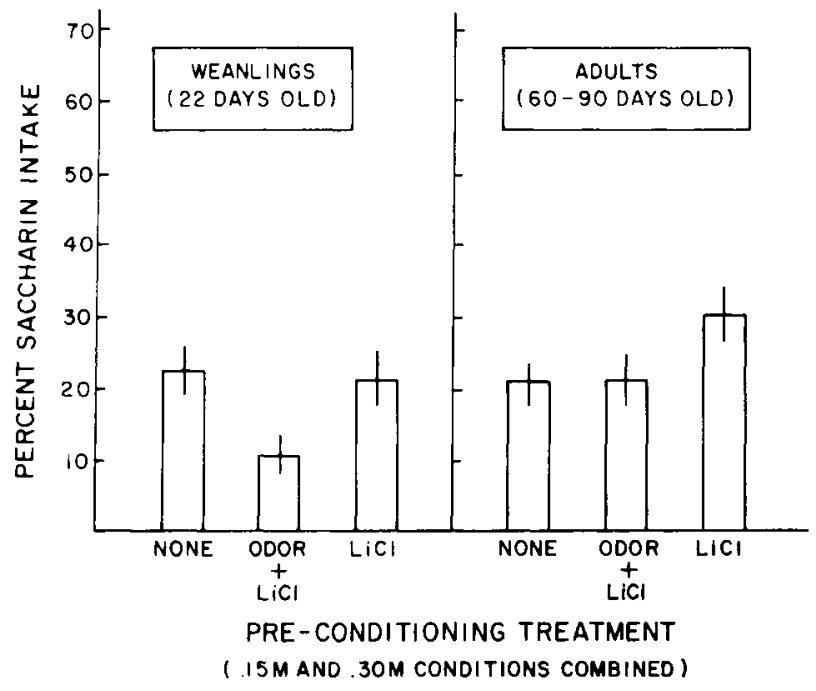

Figure 1. Mean percent saccharin preferences collapsed over LiCl intensity, for weanlings and adults given odor $+\mathrm{LiCl}, \mathrm{LiCl}$ alone, or no preexposure, in Experiment 1.

pressed significantly lower saccharin preferences than either the nonpreexposed subjects or the subjects preexposed to $\mathrm{LiCl}$ alone; the preferences for the latter two groups were statistically equivalent. Thus, among the weanlings, signaled preexposure enhanced taste aversion strength, whereas unsignaled preexposure had no significant impact.

In order to confirm the apparent ontogenetic difference in the effects of signaled preexposure, an additional analysis was performed on the combined preferences of the adults and weanlings, collapsed over drug intensity. A significant interaction was found between age and preexposure $[F(2,179)=3.9]$. Further analysis revealed that among the weanlings, the odor- $\mathrm{LiCl}$ preexposure group showed a significantly lower preference than both the nonpreexposed group and the group preexposed to $\mathrm{LiCl}$ alone. Among the adults, however, the differences among the three groups were not significant. In addition, the preferences of the weanling odor- $\mathrm{LiCl}$ group were significantly lower than those of the comparable adult group.

The principle outcome of Experiment 1 was a surprising ontogenetic difference in the effects of signaled drug preexposure. Saccharin preferences were lower in the weanlings preexposed to odor- $\mathrm{LiCl}$ than in the weanlings given either no preexposure or preexposure to $\mathrm{LiCl}$ alone. In contrast, saccharin preferences among the adults did not differ as a function of either signaled or unsignaled preexposure. Previous research on adults has indicated that drug preexposure often attenuates conditioned taste aversions, and that when preexposure is signaled, this attenuation is either reduced or eliminated (Cannon et al., 1975; Mikulka et al., 1977). The results of the present study indicate that signaled preexposure may also enhance the strength of an aversion in immature rats.

The absence of a conventional US-preexposure attenuating effect on conditioning may in part be attributable to the use of a two-bottle preference measure, which has been argued to be less sensitive to between-group differences when the groups have moderate or strong aversions (Randich \& LoLordo, 1979). It is also important to note that the subjects preexposed to $\mathrm{LiCl}$ alone received their preexposure in a test room different from that used during conditioning. This may have reduced blocking by contextual cues, a mechanism that has been suggested to account for the attenuation in conditioning often found with drug preexposure (Randich \& LoLordo, 1979; Willner, 1978). This, of course, does not explain the enhanced saccharin aversions found in the weanlings given signaled preexposure.

There is precedent, if not explanation, for an effect in immature animals similar to the present enhancement of taste conditioning by a prior odor- $\mathrm{LiCl}$ episode. Spear and Molina (1987) have reported similar effects with several different procedures that engaged a variety of sensory modalities. They found that for preweanling rats 16 days of age, the conditioning of an aversion to a black compartment was enhanced by the prior conditioning of an aversion to an odor presented in a quite different location. Adult rats showed no evidence of such transfer from olfactory to (presumably) visual conditioning. Other results reported by Spear and Molina have included transfer between tactile and gustatory conditioning among rats 4 days old, and from visual to gustatory conditioning among rats 16 days old. The tactile and gustatory stimuli given the 4-day-olds were both paired with the same US-peripheral electrical shock-and this was also the case for the visual and gustatory stimuli given the 16day-olds.

\section{EXPERIMENT 2A}

Experiment $2 \mathrm{~A}$ was designed to replicate, under somewhat different circumstances, the signaled preexposure effect found in Experiment 1 for the weanlings. One major procedural change involved the use of a one-bottle consumption test, as opposed to the two-bottle preference test used in the first experiment. In addition, the effects of signaled and unsignaled drug preexposure were assessed in separate subjects that were conditioned with or without a delay between the saccharin exposure and $\mathrm{LiCl}$. We anticipated that the delay interval during conditioning would decrease aversion strength (Baker, Baker, \& Kesner, 1977; Steinert, Infurna, Jardula, \& Spear, 1979), and we questioned whether the magnitude of such a decrease might not be less with signaled preexposure than with either unsignaled preexposure or no preexposure. Separate groups of weanlings were given odor- $\mathrm{LiCl}, \mathrm{LiCl}$ alone, or no treatment the day before the conditioning episode. On the conditioning day half of the animals in each of the three preexposure conditions received $\mathrm{LiCl}$ injections immediately after exposure to saccharin, and the remaining animals were injected after a .5-h delay. All the animals were given a one-bottle consumption test the day after conditioning. 


\section{Method}

Ninety weanlings derived from 12 litters were randomly divided into three preexposure groups. Half of the weanlings in each group were conditioned with a .5 -h saccharin- $\mathrm{LiCl}$ delay, and the other half were conditioned with a 0-h delay, yielding six groups of 15 subjects each. The preexposure procedure used in Experiment 1 was again followed. Conditioning involved .5-h exposure to saccharin, followed by either drug injection or a .5-h delay prior to drug injection. Weanlings in the 0 -delay groups immediately received their injections and were then returned to their litter cages. Weanlings in the .5-h delay groups were removed from the conditioning cages after saccharin consumption and were then placed for $.5 \mathrm{~h}$ into litter cages separate from those used to hold animals in the 0-delay groups. The delay subjects remained separated from their littermates in the 0-delay groups for an additional $2 \mathrm{~h}$. All IP injections involved administration of $.3 \mathrm{M} \mathrm{LiCl}$ at a $1 \%$ bodyweight dose level. Testing consisted of a .5-h exposure to a single bottle containing saccharin. The amount consumed by each subject during conditioning and testing was recorded to the nearest $.1 \mathrm{ml}$.

\section{Results and Discussion}

No significant differences were found among groups in the amount of saccharin consumed during conditioning. The mean test consumption for each group is presented in Figure 2. It can be seen that with a 0-min delay, the weanlings preexposed to odor- $\mathrm{LiCl}$ displayed stronger aversions than did the groups preexposed to $\mathrm{LiCl}$ alone or given no preexposure. With a .5-h delay, however, the consumption was nearly equal across the three preexposure conditions. An analysis of variance on the consumption data confirmed these observations. A significant preexposure $X$ delay interaction was obtained $[F(2,84)=3.4]$. Post hoc analysis revealed further that the interaction was the result of differences in consumption appearing between the preexposure conditions with a 0 -min delay, but not with a .5-h delay. With a 0 -h delay, the group preexposed to odor- $\mathrm{LiCl}$ drank significantly

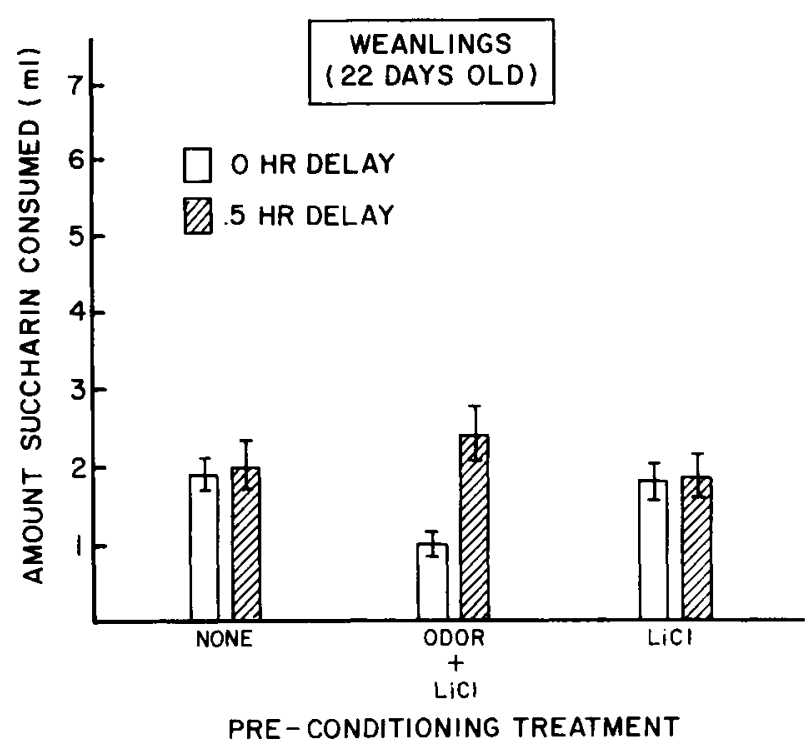

Figure 2. Mean saccharin consumption for weanlings in Experiment $2 \mathrm{~A}$. less than did the nonpreexposed group and the group preexposed to $\mathrm{LiCl}$ alone; the latter two groups drank equal amounts. With a .5-h delay, the test consumption for the three preexposure groups was equal.

The pattern of results replicated that of Experiment 1. Once again, the weanlings preexposed to odor- $\mathrm{LiCl}$ displayed enhanced saccharin aversions relative to the nonpreexposed subjects, whereas the saccharin preferences of the weanlings preexposed to $\mathrm{LiCl}$ alone were no different than those of the nonpreexposed subjects. This relationship, however, appeared only when conditioning occurred without a delay between saccharin exposure and $\mathrm{LiCl}$ injection; with a .5-h delay, enhanced aversions were not found with signaled preexposure. The latter result indicates that the enhancement of saccharin conditioning was not due to primary generalization from the previously conditioned odor, banana, to saccharin. Had such generalization occurred, the pairing of banana and $\mathrm{LiCl}$ should have yielded saccharin aversions despite the .5-h CS-US delay in the conditioning of the latter. Given the qualitative difference between these two substances, such generalization is most unlikely, but it is useful nevertheless to have this confirmed empirically.

It is possible that a change in the temporal arrangement of drug cues between preexposure and conditioning disrupted the otherwise positive transfer of an odor- $\mathrm{LiCl}$ episode to a saccharin- $\mathrm{LiCl}$ episode. Weanlings may be particularly sensitive to such changes. An alternative explanation rests on the assumption that the positive transfer depends on the concomitant representation of the taste $\mathrm{CS}$ and the representation of the odor- $\mathrm{LiCl}$ episode, assumed to be reactivated by drug effects during conditioning. If it is further assumed that the relative strength of the representation for the taste CS declined rapidly over the 30-min delay interval, then perhaps that representation was too weak to benefit from the reactivated memory of the odor- $\mathrm{LiCl}$ episode. Evidence against such a mechanism, however, includes the finding that the saccharin- $\mathrm{LiCl}$ interval did not decrease aversion strength in the nonpreexposed control subjects. The primary contribution of this experiment was, nevertheless, that the conditioning of saccharin by a saccharin- $\mathrm{LiCl}$ pairing was again enhanced by prior pairing of an unrelated odorant, banana, with the same US, $\mathrm{LiCl}$.

The absence of a facilitation effect with the delayed conditioning procedure in the weanlings contrasts with data from long-delay conditioning in adults. Westbrook and Homewood (1982) found that a prior 0-delay conditioning episode with one flavor enhanced conditioned aversion to another flavor, which had been conditioned with a 1.5- or 3-h delay separating flavor exposure and $\mathrm{LiCl}$ administration. Their procedure can be regarded as signaled preexposure, and their results indicate that, in adults, signaled preexposure decreases the delay of reinforcement gradient typically obtained with long-delay conditioning. That a similar effect was not apparent in the weanlings of this experiment can be attributed to the crossmodal nature of the signaled preexposure (odor to flavor 
conditioning), and to the fact that conditioning strength was not diminished by the .5 -h delay procedure. There is no precedent in the research on adults to indicate that long-delay taste aversion conditioning is enhanced by prior odor-drug pairings, nor that signaled flavor preexposure facilitates 0-delay conditioning. Thus, the long-delay facilitation effect reported by Westbrook and Homewood may represent a different phenomenon from that of the intermodal enhancement effect found in the weanlings.

\section{EXPERIMENT 2B}

In Experiment 2A, a one-bottle consumption test revealed a signaled preexposure enhancement effect in weanlings similar to that found with the preference test used in Experiment 1. This led us to speculate whether or not a one-bottle test would be more sensitive, and therefore more likely to detect a similar effect in adults. It has been argued that two-bottle preference tests may not distinguish between group differences in aversion strength, when the aversions range from mild to strong (Randich \& LoLordo, 1979). The two-bottle test might have obscured any real differences among the adult groups tested in Experiment 1. This might explain our failure to find either a signaled preexposure enhancement effect or a US intensity effect in the adults, despite the appearance of these effects in the weanlings. This possibility prompted us to test adults once again, but this time using the onebottle test of aversion strength.

\section{Method}

Separate groups of adults were given signaled preexposure, unsignaled preexposure, or no preexposure prior to a saccharin- $\mathrm{LiCl}$ conditioning episode. Half of the subjects in each of the three preexposure conditions received injections of $.3 \mathrm{M} \mathrm{LiCl}$, and the remaining subjects received injections of .15 M LiCl. Eight subjects were randomly assigned to each of the six groups. Other than the use of the one-bottle test, the procedure was the same as that in Experiment 1 .

\section{Results and Discussion}

The mean amount consumed by the adults in each of the three preexposure conditions (collapsed over drug intensity) appears in Figure 3 . These data were subjected to a two-factor analysis of variance, with the factors consisting of preexposure experience (signaled preexposure, unsignaled preexposure, or nonpreexposure) and drug intensity $(.15 \mathrm{M}$ or $.3 \mathrm{M} \mathrm{LiCl})$. The main effect of drug intensity was significant $[F(1,46)=43.9]$, but neither the main effect of preexposure experience nor the interaction between the two variables reached significance. This analysis confirms that the subjects given $.15 \mathrm{M} \mathrm{LiCl}(M=$ $13.0 \pm 1.1)$ drank significantly more than the subjects given $.3 \mathrm{M} \mathrm{LiCl}(M=4.5 \pm .7)$, and as can be seen in Figure 3, no differences in consumption appeared across the three preexposure conditions at either drug intensity. Thus, the use of the one-bottle test did expose an effect of drug intensity, which was not apparent with the preference test in Experiment 2A. But as in Experiment 1, there

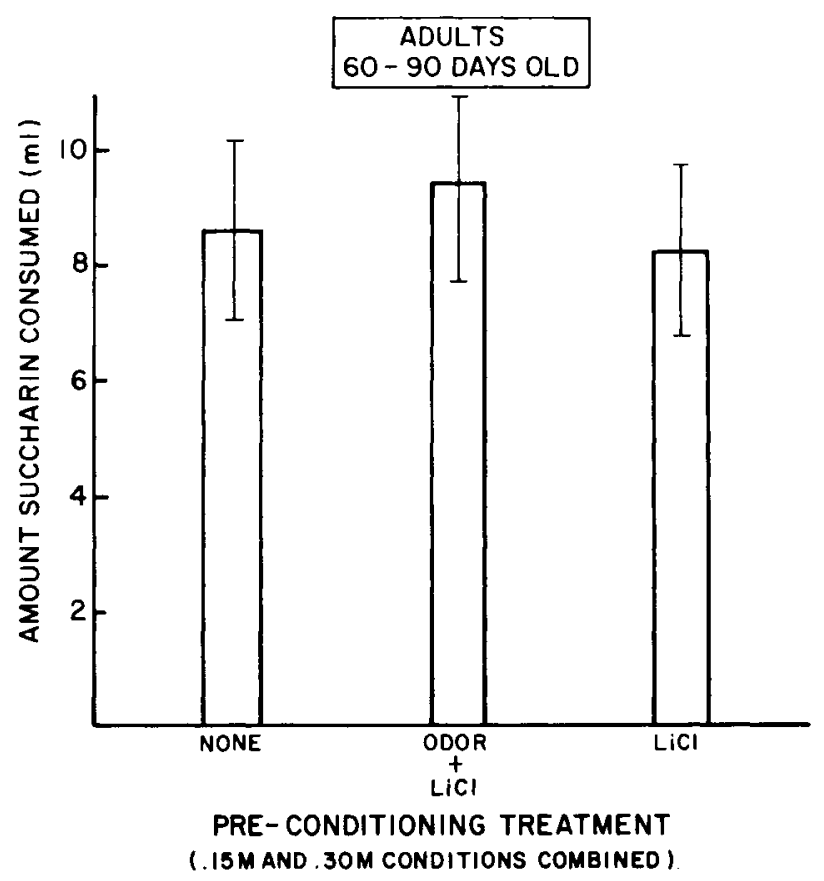

Figure 3. Mean saccharin consumption for adults in Experiment $2 B$.

was no evidence of either an enhancement or attenuation of aversion strength due to signaled or unsignaled drug preexposure. These data once again contrast with the results with weanlings.

\section{EXPERIMENT 3}

Experiments 1 and $2 \mathrm{~A}$ established that the weanlings preexposed to odor- $\mathrm{LiCl}$ showed a subsequent enhancement in the strength of a conditioned saccharin aversion, an effect not apparent in the weanlings preexposed to $\mathrm{LiCl}$ alone. This enhancement effect did not appear when the conditioning involved a delay between the exposure to saccharin and the injection of $\mathrm{LiCl}$. In this condition, there was a change in the temporal arrangement of the cue-drug pairing between preexposure and conditioning. During preexposure, these animals experienced drug injectionsand presumably the drug effect-in close temporal contiguity with the odor stimulus; but during conditioning, the contiguity between the taste CS and the drug was reduced. This change might have reduced the perceived similarity of the preexposure and conditioning episodes, so that positive transfer of preexposure to conditioning did not occur. Perhaps any marked difference in the nature of the preexposure and conditioning episodes would eliminate the enhancement effect. The purpose of Experiment 3 was to examine this possibility more explicitly.

Research on adults has indicated that drug intensity can influence both the degree of attenuation found with drug preexposure and the absolute magnitude of aversion strength. Cannon et al. (1975), using a factorial design, exposed adult rats to injections of either $.12 \mathrm{M}$ or $.36 \mathrm{M}$ 
$\mathrm{LiCl}$ prior to conditioning with either $.12 \mathrm{M}$ or $.36 \mathrm{M} \mathrm{LiCl}$. They found that the degree of attenuation was a direct function of the drug intensity used during preexposure and an inverse function of the drug intensity used during conditioning. There was no indication of an interaction between preexposure and conditioning intensities. A more recent study by Klein, Mikulka, and Lucci (1986) did find such an interaction. These reseachers found less attenuation of a conditioned taste aversion when the preexposure drug intensity was lower, and more when it was equal to or much higher than the drug intensity used during conditioning.

The current experiment was designed to test the influence of changing drug intensity between preexposure and conditioning for both signaled and unsignaled preexposure in weanlings. In a factorial design, separate groups of weanlings were exposed to odor $-\mathrm{LiCl}, \mathrm{LiCl}$ alone, or no drug prior to a saccharin- $\mathrm{LiCl}$ conditioning episode. The preexposed groups received either $.15 \mathrm{M}$ or $.3 \mathrm{M} \mathrm{LiCl}$ during preexposure, and they received either $.15 \mathrm{M}$ or $.3 \mathrm{M} \mathrm{LiCl}$ during conditioning. If the enhancement effect found in the previous experiments depended on the congruency of the preexposure and conditioning episodes, and if such congruency could be reduced by changing the drug intensity from the one episode to the other, then the enhancement effect would decline or disappear under such conditions.

\section{Method}

Two hundred weanlings derived from 25 litters were randomly assigned to each of 10 groups. The nonpreexposed groups received no drug prior to conditioning, and they received saccharin paired with either $.15 \mathrm{M}$ or $.3 \mathrm{M} \mathrm{LiCl}$ during conditioning. The day before conditioning, 4 of the preexposed groups received an odor- $\mathrm{LiCl}$ pairing, and the remaining 4 groups received $\mathrm{LiCl}$-alone injections. The preexposed groups received either $.15 \mathrm{M}$ or $.3 \mathrm{M} \mathrm{LiCl}$ during preexposure, and they were given either the same or the other drug concentration during conditioning. This arrangement yielded signaled and unsignaled preexposed groups for each of the following combinations of drug intensity: $.15 \mathrm{M}-.15 \mathrm{M}, .3 \mathrm{M}-.3 \mathrm{M}$, $.15 \mathrm{M}-.3 \mathrm{M}, .3 \mathrm{M}-.15 \mathrm{M} \mathrm{LiCl}$. The general preexposure and conditioning procedures described for Experiment 1 were again followed. Testing occurred the day after conditioning; it consisted of a two-bottle preference test.

\section{Results and Discussion}

The mean saccharin preferences, collapsed over conditioning intensity, are presented in Figure 4. An analysis of variance was performed on the preference scores for the $\mathbf{1 0}$ groups. For this analysis, the groups were arranged according to two factors: conditioning intensity $(.15 \mathrm{M}$ or $.3 \mathrm{M} \mathrm{LiCl})$ and preexposure experience (none, signaled same intensity, signaled different intensity, unsignaled same intensity, and unsignaled different intensity). This analysis revealed significant main effects for conditioning intensity $[F(1,190)=15.7]$ and preexposure experience $[F(4,190)=2.7]$. The conditioning intensity $X$ preexposure experience interaction was not significant. Further analysis revealed that the groups preexposed to odor- $\mathrm{LiCl}$ and conditioned with the same $\mathrm{LiCl}$ intensity

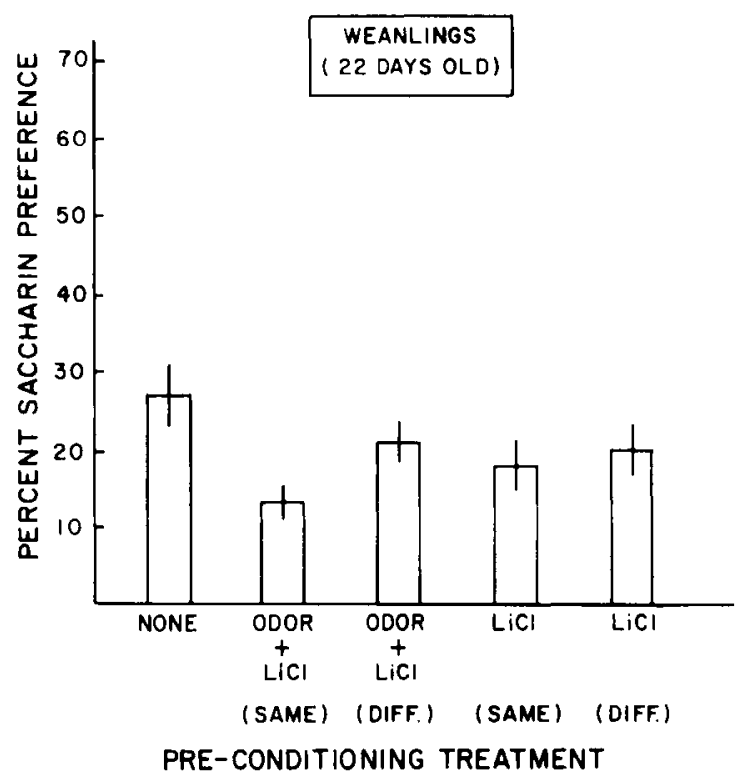

Figure 4. Mean percent saccharin preferences for weanlings in Experiment 3. Same refers to weanlings given the same $\mathrm{LiCl}$ concentration during preexposure and conditioning; different refers to weanlings preexposed and conditioned with different concentrations of $\mathbf{L i C l}$.

showed significantly lower saccharin preferences than the nonpreexposed subjects did. None of the remaining group comparisons differed significantly. Overall, the subjects conditioned with $.3 \mathrm{M} \mathrm{LiCl}(M=14.5)$ displayed significantly lower preferences than did the subjects conditioned with $.15 \mathrm{M} \mathrm{LiCl}(M=25.5)$.

As in the findings for the adults, and consistent with the data from Experiment 1, the intensity of the US ( $\mathrm{LiCl})$ affected the strength of a conditioned taste aversion in the weanlings. The weanlings conditioned with $.15 \mathrm{M} \mathrm{LiCl}$ showed an overall higher saccharin preference than did the weanlings conditioned with $.3 \mathrm{M} \mathrm{LiCl}$. As in Experiments 1 and $2 \mathrm{~A}$, saccharin preferences were decreased in the weanlings by preexposure to an odor-drug pairing, but only when the drug intensity remained the same for both preexposure and conditioning. In contrast, the weanlings preexposed to $\mathrm{LiCl}$ alone displayed saccharin preferences no different from those shown by nonpreexposed subjects.

The weanling rats in this experiment transferred an odor- $\mathrm{LiCl}$ experience to a saccharin- $\mathrm{LiCl}$ experience. But they did so only if the US associated with each of these CS events was the same. Spear and Molina (1987, p. 97) have reported a similar effect in transfer between olfactory and visual stimuli: visual conditioning was enhanced by prior olfactory conditioning only if the US in each case was the same-either footshock or citric acid infused into the mouth. When the conditioning to the olfactory stimulus involved footshock and that to the visual stimulus involved citric acid, or vice versa, transfer between the olfactory and visual stimuli did not occur. In the present experiment, an odor-drug experience did not facilitate 
subsequent taste aversion conditioning when the odor and the taste were not accompanied by the same US-that is, if the US was $.15 \mathrm{M} \mathrm{LiCl}$ in one case and $.3 \mathrm{M} \mathrm{LiCl}$ the other. The difference between $.15 \mathrm{M}$ and $.3 \mathrm{M}$ may be more than quantitative, since the latter, but not the former, is hypertonic and hence may cause peripheral as well as internal discomfort along with the injection of the US.

\section{GENERAL DISCUSSION}

The central observation made in each of these experiments was that conditioning of an aversion to the taste of saccharin was enhanced by prior experience of an odor paired with $\mathrm{LiCl}$ in weanlings but not adults. Similar ontogenetic differences in olfactory to gustatory transfer have been shown by Molina and his colleagues (e.g., Molina, Serwatka, \& Spear, 1984; Molina, Serwatka, Spear, \& Spear, 1985). It is likely, however, that the latter results reflect greater primary generalization between the odor and taste of ethanol for infants than for adults. In the Molina et al. studies, immediate transfer was observed, but in the present experiments, no immediate transfer was apparent: the consumption of saccharin during the conditioning episode was unaffected by the prior odor-LiCl episode. Instead, the transfer involved enhanced saccharin aversions following the taste- $\mathrm{LiCl}$ conditioning in weanlings preexposed to an odor- $\mathrm{LiCl}$ episode. The results of Experiment $2 \mathrm{~A}$ also showed that prior odor- $\mathrm{LiCl}$ experience was not in itself sufficient to induce the gustatory aversion, a circumstance also implied by the results of Experiment 3.

The transfer from olfactory to gustatory conditioning observed in the present experiments could be said to be an instance of acquired equivalence or "mediated generalization," in which a common US associated with both the olfactory and gustatory events provided the mediation. In this instance, the cross-modal transfer was limited to the weanlings, but in other situations, adult rats and adults of other species have shown similar facilitation. For example, in adult rats, transfer has been obtained between auditory and visual signals that share common temporal attributes (Church \& Meck, 1984), and between different tastes that have been paired with the same drug (Westbrook \& Homewood, 1982). Positive transfer from visual conditioning to auditory conditioning has also been obtained with eyelid conditioning in adult rabbits (Kehoe \& Holt, 1984; Kehoe, Morow, \& Holt, 1984; Holt \& Kehoe, 1985). The latter studies have shown that trace conditioning with an auditory CS is facilitated by prior trace conditioning with a visual CS. It is unclear whether the transfer that appeared as an increase in the acquisition of the auditory conditioning in the studies by Kehoe and his colleagues reflects the same phenomenon as the relatively immediate transfer observed for only the younger animals in the present experiments.

That the weanlings displayed a transfer effect not apparent in the adult rats is the paramount finding in this study. As suggested above, in adult rats, there is evidence of positive transfer between the conditioned aversions to two different (tasted) flavors. Westbrook and Homewood (1982) found that a taste aversion conditioned with a long CS-US delay was enhanced by prior 0-delay conditioning to a different flavor. Thus it is clear that under some circumstances adult rats do benefit from prior conditioning, although the differences between these circumstances and those of the present experiments should be emphasized. The present experiments involved intermodal transfer that was observed only with 0-delay conditioning, whereas the Westbrook and Homewood experiments involved intramodal transfer, observed only as a decrease in the attenuation otherwise obtained with long CS-US intervals. The degree to which these effects are actually separate phenomena requires additional empirical study. The claim we want to make, therefore, is not that weanlings necessarily show a kind of learning not evident in adults, but rather that within the present experimental context an age-related difference in transfer was unambiguously evident, and that the type of transfer obtained with the weanlings here has yet to be demonstrated with adults.

Four points relevant to the interpretation of these results need to be addressed. The first is the absence of an impairment in taste-aversion conditioning among animals given unsignaled $\mathrm{LiCl}$ prior to a pairing of a novel taste and $\mathrm{LiCl}-$ the conventional US-preexposure effect. The absence of this effect in the present experiments can be attributed to conditions in our procedures that are known to minimize or eliminate the US-preexposure effect. Prior exposure to the US was always given in a different room (and hence a different context) from that used for the saccharin-LiCl conditioning. We did this to eliminate the possiblity that following the pairing of the odor and $\mathrm{LiCl}$ for animals in the signaled condition, traces of the odorant might be present during subsequent saccharin- $\mathrm{LiCl}$ conditioning. It is known that a change in context between US preexposure and conditioning decreases or eliminates the US-preexposure effect (Randich \& LoLordo, 1979).

Second, one might ask whether there is some kind of peculiar relationship between the odor of banana and the taste of saccharin that could promote their treatment as equivalent substances. The results of Experiments $2 \mathrm{~A}$ and 3 argue against the possibility of primary stimulus generalization between these two substances. In Experiment 2A, it was shown that the facilitation effect was not expressed when the saccharin conditioning involved a .5-h delay between the CS and US. In Experiment 3, it was found that facilitation did not appear unless the doses of $\mathrm{LiCl}$ paired with the odor and the taste were the same. If the transfer of conditioning had been accomplished by simple primary generalization it ought to have occurred regardless of the relationship between the USs.

The third point is the possibility that the transfer from olfactory to gustatory conditioning was greater for the weanlings than for the adults because the olfactory conditioning was stronger for the weanlings. Although we did not measure this conditioning directly in the present 
experiments, there is no reason to expect this possibility. Moreover, greater strength of odor conditioning is itself not sufficient to yield more transfer. It was shown in Experiment 3 that there was no greater transfer when the odor aversion was formed by a relatively large US $(.3 \mathrm{M}$ vs. .15M, a difference in US strength sufficient to yield differences in conditioning).

Finally, two different types of explanation can be considered for the age-related differences obtained in these experiments. First, the results may reflect a quantitative difference between the information processing of weanlings and of adults. Mechanisms that have been offered to account for the various transfer effects obtained in other circumstances may be applicable to the present situation, with the added assumption that such mechanisms may have been more effective or may have had a greater impact on weanlings than on adults. For example, perhaps some sort of general attention mechanism (Thomas, 1970), such as reduced interference from incidental stimuli (Mackintosh, 1973) or learning-to-learn (Harlow, 1959), may have operated to a greater extent among the weanlings than among the adults. Then, under appropriate parameters, similar intermodal transfer could be obtained with adults. Yet although there is no doubt that intermodal transfer is possible in adults, these factors are unlikely to account for the relatively greater strength of this effect in weanlings and preweanlings; Harlow's work, for instance, clearly shows far less rapid learning-to-learn in more immature monkeys (Harlow, 1959).

As another example of this first type of explanation, it has been suggested to us that perhaps the weanlings' transfer was the result of enhanced context aversion, relative to the context aversion in adults. That is, the greater novelty of the wire test cages for the weanlings could have produced a stronger aversion to the test context, which could have been potentiated by the odor-LiCl experience. The context aversion could have combined with the saccharin aversion to produce enhanced taste aversions. The use of a two-bottle preference test would complicate such an interpretation, but there are even stronger grounds for dismissing this proposal. Specifically, the transfer effect was eliminated by changes in both the saccharin- $\mathrm{LiCl}$ interval (Experiment 2A) and the drug intensity in preexposure and conditioning (Experiment 3 ). The absence of between-group differences in the initial consumption of saccharin during the conditioning episode also undermines the context interpretation, given that an aversion to the context should have influenced general consumption within that context. Finally, there was no indication that the weanlings preexposed to $\mathrm{LiCl}$ alone expressed any stronger taste aversions than did the nonpreexposed weanlings, which might have been expected if a context aversion had in some way mediated the taste aversion. Thus we believe that the role of context aversion, although not irrelevant, clearly does not provide an adequate explanation for our results.

A second type of explanation assumes that the ontogenetic differences in transfer reflect a qualitative difference between the information processing of weanlings and of adults. There is a precedent for arguing that the representations, the representation process, or both, may differ for older and younger animals, as has been suggested with respect to infantile amnesia (Gordon, 1979; Spear, 1978, 1979). The present results may reflect such representational differences. For example, weanlings may be more sensitive than adults to the amodal properties of stimuli, and so they may be more likely to equate, for instance, the novelty or the hedonic properties of odors and tastes. Thus, in the present situation, after the conditioning to saccharin, the weanlings may have treated the odor and taste as functionally equivalent. The process of establishing functional equivalence, however, may also be mediated by a common consequence associated with each stimulus. That is, the equivalence attribution could not have occurred until the consequence of $\mathrm{LiCl}$ was experienced following saccharin consumption. This would explain the enhanced saccharin aversion following conditioning, despite the absence of an initial aversion to saccharin preceding the $\mathrm{LiCl}$ administration. Through this process the weanlings' taste aversion following odor $-\mathrm{LiCl}$ preexposure might have been comparable in strength to an aversion established with two successive saccharin- $\mathrm{LiCl}$ conditioning episodes. The functional equation of two or more sensory events that can otherwise be discriminated, perhaps on the basis of common amodal properties, may be vulnerable to developmental change, and may be especially prevalent in animals of weanling age or younger (Gibson, 1984; Spear \& Molina, 1987; Spear, Kraemer, Molina, \& Smoller, 1988). Obviously this or any other theoretical account of these results requires additional empirical evaluation, but the present findings remain as a contribution to our factual knowledge of ontogenetic differences in learning and memory.

\section{REFERENCES}

BAKer, L. J., BAKer, T. B., \& KeSner, R. P. (1977). Taste-aversion learning in young and adult rats. Journal of Comparative \& Physiological Psychology, 91, 1168-1178.

Braveman, N.S. (1975). Formation of taste aversions in rats following prior exposure to sickness. Leaming \& Motivation, 6, 512-534. Cannon, D., Berman, R., Baker, T., atrinson, C. (1975). Effect of preconditioning unconditioned stimulus experience on learned taste aversions. Joumal of Experimental Psychology: Animal Behavior Processes, 104, $270-284$.

Cappell, H. D., \& Leblanc, A. E. (1975). Conditioned aversion by amphetamine: Rates of acquisition and loss of attenuating effects of prior exposure. Psychopharmacologia, 43, 157-162.

Church, R. M., Meck, W. H. (1984). Acquisition and cross-modal transfer of classification rules for temporal intervals. In M. L. Commons, A. R. Wagner, \& R. A. Hermstein (Eds.), Quantitative analysis of behavior: Discriminative processes (Vol. 4). Cambridge, MA: Ballinger.

ELKINS, R. L. (1974). Conditioned flavor aversions to familiar tap water in rats: An adjustment with implications for aversion therapy treatment of alcoholism and obesity. Journal of Abnormal Psychology, 83, 411-417.

Gemberling, G. A., \& Domjan, M. (1982). Selective associations in one-day old rats: Taste-toxicosis and texture-shock aversion learning. Joumal of Comparative \& Physiological Psychology, 96, 105-113.

Gemberung, G. A., Doman, M., Amsel, A. (1980). Aversion leaming in 5-day old rats: Taste-toxicosis and texture-shock associations. Journal of Comparative \& Physiological Psychology, 94, 734-745. 
GiBson, E. J. (1984). Development of knowledge about intermodal unity: Two views. In L. Libon (Ed.), Piaget and the foundations of knowledge (pp. 19-41). Hillsdale, NJ: Erlbaum.

GoRDon, W. C. (1979). Age: Is it a constraint on memory content? In N. E. Spear \& B. A. Campbell (Eds.), Ontogeny of learning and memory (pp. 271-288). Hillsdale, NJ: Erlbaum.

HaRLow, J. F. (1959). The development of learning in the rhesus monkey. Aversion Scientist, 47, 459-479.

Hofpmann, H., Molina, J. C., Kucharski, D., \& Spear, N. E. (1987). Further examination of ontogenetic limitations on conditioned taste aversion. Developmental Psychobiology, 20, 455-464.

Holt, P. E., \& KeноE, E. J. (1985). Cross-modal transfer as a function of similarities between training tasks in classical conditioning of the rabbit. Animal Learning \& Behavior, 13, 51-59.

KeHOE, E. J., \& HoLT, P. E. (1984). Transfer across CS-US intervals and sensory modalities in classical conditioning of the rabbit. Animal Learning \& Behavior, 12, 122-128.

Kehoe, E. J., Morrow, L. D., \& Holt, P. E. (1984). General transfer across sensory modalities survives reductions in the original conditioned reflex in the rabbit. Animal Learning \& Behavior, 12, 129-136.

KLeIN, S. B., MikulKa, P. J., \& LuCCI, K. (1986). Influence of lithium chloride intensity on unconditioned stimulus-alone interference in a flavor aversion paradigm. Learning \& Motivation, 17, 76-90.

Kraemer, P. J., HoffmanN, H., \& Spear, N. E. (1988). Attenuation of the CS-preexposure effect after a retention interval in preweanling rats. Animal Learning \& Behavior, 16, 185-190.

Mackintosh, N. J. (1973). Stimulus selection: Learning to ignore stimuli that predict no change in reinforcement. In R. A. Hinde \& J. Stevenson-Hinde (Eds.), Constraints on learning (pp. 75-100). London: Academic Press.

MikulkA, P. J., Leard, B., \& Klein, S. B. (1977). Illness alone exposure as a source of interference with acquisition and retention of a taste aversion. Joumal of Experimental Psychology: Animal Behavior Processes, 3, 189-200.

Molina, J. C., Serwatka, J., \& Spar, N. E. (1984). Changes in alcohol intake resulting from prior experiences with alcohol odor in young rats. Pharmacological Biochemistry, 1, 387-391.

Molina, J. C., Serwatka, J., Spear, L., SPear, N. E. (1985). Differential ethanol olfactory experiences affect ethanol ingestion in preweanlings but not in older rats. Behavioral \& Neural Biology, 44, 90-100.

Randich, A., Lolordo, V. M. (1979). Preconditioning exposure to the unconditioned stimulus affects the acquisition of a conditioned emotional response. Learning \& Motivation, 10, 245-275.

Riley, A. L., JACOBS, W. J., \& LoLoRDO, V. M. (1976). Drug eXposure and the acquisition and retention of a taste aversion. Journal of Comparative \& Physiological Psychology, 90, 799-807.

SPEAR, N. E. (1978). Processing memories: Forgetting and retention. Hillsdale, NJ: Erlbaum.

SPEAR, N. E. (1979). Memory storage factors in infantile amnesia. In G. Bower (Ed.), The psychology of learning and motivation (Vol. 13, pp. 91-154). New York: Academic Press.

Spear, N. E., Kraemer, P. J., Molina, J. C., \& Smoller, D. E. (1988). Developmental change in learning and memory: Infantile disposition for "unitization." In J. DeLacour \& J. C. S. Levy (Eds.), Systems with learning and memory abilities. Amsterdam: Elsevier/ North-Holland.

Spear, N. E., \& Molina, J. C. (1987). The role of sensory modality in the ontogeny of stimulus selection. In N. A. Krasnegor, E. M. Blass, M. A. Hofer, \& W. P. Smotherman (Eds.), Perinatal development: A psychobiological perspective (pp. 83-100). Orlando, FL: Academic Press.

Steinert, P. A., Infurna, R. N., Jardula, M. F., Spear, N. E. (1979). Effects of CS conditioning on long delay leaming in preweanling and adult rats. Behavioral \& Neural Biology, 27, 487-502.

Tномаs, D. R. (1970). Stimulus selection, attention and related matters. In J. H. Reynierse (Ed.), Current issues in animal learning (pp. 311-356). Lincoln: University of Nebraska Press.

WESTBROOK, R. F., \& HomewOOD, J. (1982). The effects of a flavour toxicosis pairing upon long-delay flavour aversion learning. Quarterly Journal of Experimental Psychology, 34B, 59-75.

WILlNER, J. A. (1978). Blocking of a taste aversion by prior pairings of exteroceptive stimuli with illness. Learning \& Motivation, 9, 125-140.

(Manuscript received January 13, 1988; revision accepted for publication July 22,1988 .) 